\title{
En bloc right hemicolectomy with pancreatoduodenectomy for right-sided colon cancer invading duodenum
}

\author{
Xiao-Luan Yan', Kun Wang ${ }^{1}$, Quan Bao ${ }^{1}$, Hong-Wei Wang ${ }^{1}$, Ke-min Jin' ${ }^{1}$ Jun-Yun Wang ${ }^{2,3}$ and Bao-Cai Xing ${ }^{1 *}$ (D)
}

\begin{abstract}
Background: En bloc right hemicolectomy with pancreatoduodenectomy (RHCPD) is the optimum treatment to achieve the adequate margin of resection (RO) for locally advanced right-sided colon cancer with duodenal invasion. Information regarding the indications and outcomes of this procedure is limited.

Method: In this retrospective study, 2269 patients with right colon cancer underwent radical right colectomy between October 2010 and May 2019, in which 19 patients underwent RHCPD for LARCC were identified. The overall survival (OS), disease-free survival (DFS), operative mortality, postsurgical complications, gene mutational analysis, and prognostic factors were evaluated. Survival was estimated using Kaplan-Meir method.

Results: Of these 19 patients who underwent LARCC, the OS was $88 \%, 66 \%$, and $58 \%$ at 1, 3, and 5 years. The DFS was $72 \%, 56 \%$, and $56 \%$ at 1, 3, and 5 years. The median operative time was 320 min (range: $222-410$ min), and the median operative blood loss was $268 \mathrm{~mL}$ (range: 100-600 mL). The OS was significantly better among patients with well-differentiated tumor, N0 stage, and high microsatellite instability (MSI) and in patients who received adjuvant chemotherapy. The major postoperative complications occurred in 8 patients (42\%), with pancreatic fistula (PF) being the most common. On the basis of the univariate analysis, poorly differentiated tumor, regional lymph node dissemination, MSI status, and no perioperative chemotherapy were the significant predictors of poor survival $(P<0.05)$.
\end{abstract}

Conclusions: This study suggests that RHCPD is feasible and can achieve complete tumor clearance with favorable outcome, particularly in patients with lymph node-negative status.

Keywords: En bloc resection, Pancreatoduodenectomy, Locally advanced right-sided colon cancer right hemicolectomy, Survival

\section{Background}

Colorectal cancer (CRC) ranks the third among malignancies in the world, and the mortality rate of patients with advanced CRC is high [1-3]. Adjacent organ invasion is found to be $5-24 \%$ in CRC patients $[4,5]$, and carcinoma of the right colon rarely invades adjacent viscera,

\footnotetext{
*Correspondence: xingbaocai88@sina.com

1 Key Laboratory of Carcinogenesis and Translational Research (Ministry of Education/Beijing), Hepatopancreatobiliary Surgery Department I, Peking University Cancer Hospital \& Institute, Beijing, China

Full list of author information is available at the end of the article
}

the incidence of which is reported to be $0.9-2.6 \%$ [5-7]. Surgery is considered the first choice for CRC if possible [3]. Non-radical resection and blunt mobilization of colon cancer from adherent organs are associated with tumor recurrence, and the prognosis of such patients is poor [8-10]. En bloc resection is the curative resection for locally advanced CRC that has adhered to and/ or invaded adjacent structures without distant metastasis. LARCC (locally advanced right-sided colon cancer) can involve the duodenum, pancreas, and other organs. Under such conditions, it is necessary to perform 
multivisceral or extended resection to achieve tumor negative margin of resection (R0).

We believe that radical RHCPD (right hemi-colectomy with pancreatoduodenectomy), first reported in 1953, is the preferred choice to achieve R0 resection of LARCC [11-13]. Despite the complexity of RHCPD, acceptable mortality and morbidity rates have been reported in several studies $[7,11,14]$. Nevertheless, clinicopathological findings and long-term outcomes of LARCC patients treated by RHCPD are rarely reported [5, 12, 15-18]. In China, the histologic findings and long-term survival of LARCC treated by RHCPD are also rarely reported $[5,12,19]$. Moreover, the potential relationship between the clinicohistologic-genetic status and prognosis is unknown. In this retrospective study, we aimed to evaluate RHCPD in achieving radical tumor removal of LARCC patients with favorable outcomes and to identify prognostic factors of such patients with malignant involvement of adjacent organs as well as their gene expression and pathologic characteristics.

\section{Methods}

\section{Patient characteristics}

Patients who were diagnosed with primary right-sided colon cancer and accepted radical right colectomy between October 2010 and May 2019, at the Beijing Cancer Hospital, were retrospectively analyzed. The data of demographics, estimated blood loss, duration of surgery, adjuvant and/or neoadjuvant chemotherapy, tumor pathology, mortality, morbidity, and long-term outcomes were collected. Inclusion criteria: (1) no metastasis revealed by preoperative imaging; (2) potential curative resections; (3) colon carcinoma confirmed histologically; (4) T4 malignancy either to pancreas or duodenum revealed by biopsy; (5) available radiologic data at follow-up in our institution. Exclusion criteria: (1) local recurrent tumor; (2) distant metastasis; (3) secondary involvement of the pancreatic head and/or duodenum other than direct infiltration. The protocol was approved by the ethics committee of Beijing Cancer Hospital, and all the patients signed the written informed consent. The 1964 Helsinki declaration and its subsequent amendments were followed.

\section{Diagnosis and indications for RHCPD}

Local tumor infiltration was evaluated using preoperative computed tomography (CT). Loss of the fat space between the duodenum and the recurrent tumor, protrusion of a nodular mass into the duodenum, or involvement of the head of the pancreas indicated that the tumor involved the duodenum and/or the head of the pancreas. CEA (carcinoembryonic antigen) and CA19-9 (cancer antigen 19-9) levels of all patients were detected before surgery. Colonoscopy and histopathologic determination of the tumor were performed before surgery to confirm colon cancer justifying the need for RHCPD. Below are indications for RHCPD: (1) histologic confirmation of colon carcinoma before surgery; (2) impossible to dissociate the tumor from the pancreas and/or duodenum with gentle mobilization; (3) feasible radical resection according to preoperative evaluation and no distant metastasis; and (4) no severe comorbidity able to tolerate a radical multivisceral excision $[5,16,17]$.

\section{Surgical procedure for RHCPD \\ Resection}

We first performed a Cattell-Brasch maneuver, and an extended Kocher maneuver was then used to mobilize the duodenum fully [14]. We assessed the amount of infiltration into the pancreas and/or and duodenum and resectability of LARCC after complete mobilization of the right colon and duodenum without removal of the adherent organs. After R0 resection based on the standard procedures, RHCPD was performed. If the SMV (superior mesenteric vein) and/or portal vein was involved, the mesentericoportal vein was also dissected followed by an end-to-end anastomosis.

\section{Reconstruction}

Following the methods of modified Child's reconstruction, we performed reconstruction with an end-to-side pancreaticojejunostomy or pancreaticogastrostomy, which depended on the pancreatic duct. During pancreatojejunostomy procedures, the stent of the pancreatic duct was used, which is an intraluminal stent left to fall out on its own. Stapled side-to-side anastomosis of the ileum and transverse colon was introduced for the bowel reconstruction. After the procedures above, we inserted rubber drains near the pancreatic and biliary anastomoses, and the incision at the abdominal wall was sutured $[5,14,16]$.

\section{Pathology and gene testing}

Based on the classification of AJCC (American Joint Committee of Cancer), the tumor stage was evaluated [20]. Postoperative complications, such as DGE (delayed gastric emptying), PF (pancreatic fistula), and intraabdominal abscess, were evaluated. Postoperative PF and DGE were defined based on the International Study Group on Pancreatic Fistula Definition and the International Study Group of Pancreatic Surgery [21-23], respectively. If infected pus and fluid inside the abdominal cavity was collected, intraabdominal abscess was diagnosed (Additional file 1).

Tumor cellularity was determined using formalin-fixed, paraffin-embedded blocks. Tumors were macrodissected 
for removal of normal tissues, and samples containing $>20 \%$ neoplastic cells were harvested. Sample preparation, exome capture, library construction, bioinformatics analyses and NGS (next-generation sequencing) of cancer and normal samples were carried out at GloriousMed Holdings Co., Ltd. (Pudong New Area, Shanghai). NRAS, KRAS, BRAF, HER4 and HER2 mutations were determined using NGS.

Microsatellite instability (MSI) Analysis System Version 1.2 (Promega, Madison, WI) was used to determine MSI (microsatellite instability), which included five pseudomonomorphic mononucleotide repeats (NR-24, NR-21, BAT-26, MONO-27, and BAT-25). Over 2 of 5 altered markers indicated high MSI (MSI-H).

\section{Follow-up}

All patients were followed up after surgery, with a 3-month interval during the first 2 years, then 6-month interval during the subsequent 3 years, and at least 1-year interval thereafter. During each follow-up, CEA and CA19-9 testing, abdominal CT or ultrasound, chest radiography, and physical examination were carried out. The standard protocol was followed during the follow-up [24]. Patients underwent colonoscopy annually at outpatient clinics.

\section{Primary and secondary outcomes}

Overall survival (OS) was deemed as the primary endpoint. The secondary endpoints included 30-day postoperative mortality, postsurgical complications, DFS (disease-free survival), prognostic factors and gene testing results.

\section{Statistical analysis}

SPSS v.16.0 software (provided by SPSS, Chicago, IL) was used for data analysis. The median (range) was used express numerical data. The KM (Kaplan-Meier) method was used to assess the survival rate. Univariate analysis was performed to assess prognostic variables, and $P<0.05$ indicated statistical significance.

\section{Results}

\section{Patients characteristics}

Between October 2010 and May 2019, 2269 patients with primary right-sided colon cancer underwent radical RC at the Beijing Cancer Hospital. Among them, 19 patients (12 men and 7 women) underwent RHCPD for LARCC with direct infiltration into the duodenum and/or pancreas. The median age of the patients was 60 years (range, 35-75 years). The tumors were located in the ascending colon (3 patients) and hepatic flexure (16 patients). Direct tissue invasion by the tumor into the duodenum was observed in all the patients, pancreas in 4 patients, the liver in 2 patients, and the SMV in 1 patient. The median preoperative CEA was $5.7 \mathrm{ng} / \mathrm{mL}$ (range: $0.9-18.5 \mathrm{ng} /$ $\mathrm{mL}$ ), and CA19-9 was $43.2 \mathrm{IU} / \mathrm{mL}$ (range: $0.5-228.4 \mathrm{IU} /$ $\mathrm{mL}$ ). During presentation, 13 patients had anemia, and 8 had abdominal pain. Other prominent symptoms were history of significant weight loss $(n=7)$, abdominal distension $(\mathrm{n}=5)$, and vomiting $(\mathrm{n}=5)$.

\section{Overall survival and disease-free survival}

The median follow-up time was 39 moths (range: 5-112 months). During the follow-up period, 6 patients died from abdominal or liver metastases. The median survival time was 76 months (95\% CI 53.3: 98.3). The 1-, 3 -, and 5 -year OS was $88 \%, 66 \%$, and $58 \%$, and DFS was $72 \%, 56 \%$, and $56 \%$ respectively (Fig. 1). Among the 13 patients who were still alive at the last follow-up, 4 survived $>5$ years with no recurrence (Cases $2,3,7$, and 8 ).

On the basis of the KM-survival curves between various groups, the survival was significantly better among patients with well- or moderately differentiated tumor $(P=0.03)$ (Fig. 2A), N0 stage $(P=0.01)$ (Fig. 2B), MSI-H $(P=0.047)$ (Fig. 2C) and in patients who received chemotherapy $(P=0.027)$ (Fig. 2D).

\section{Postoperative complications and treatment}

The treatments and outcomes data of the patients are listed in Table 1 . The median operative time was $320 \mathrm{~min}$ (range: $222-410 \mathrm{~min}$ ), and the median operative blood loss was $268 \mathrm{~mL}$ (range: 100-600 mL). Blood was transfused intraoperatively in 11 patients with an average amount of $2.5 \mathrm{U}$ (range: 2-6 U), also due to preoperative anemia. The postoperative hospital stay was 23.5 days (range: 11-45 days). None of the patients died during the postoperative 30 days.

Major postoperative complications occurred in 8 patients (42\%) with clinically significant PF being the

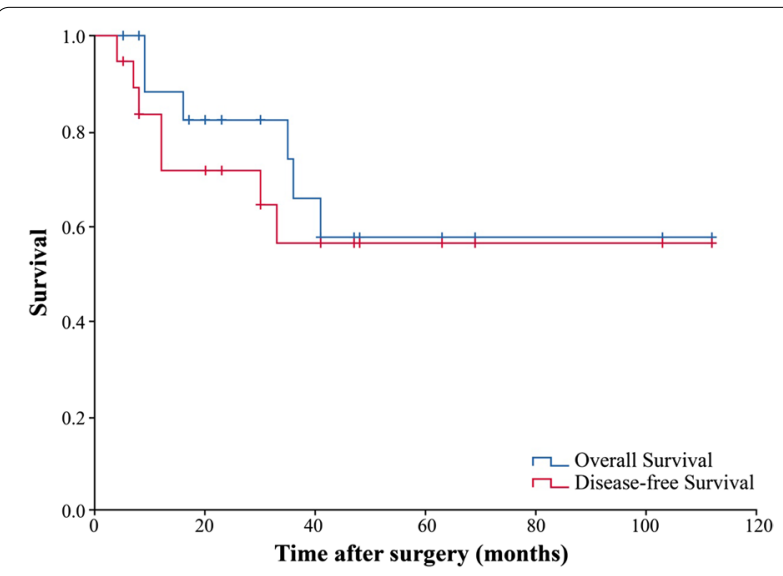

Fig. 1 Overall survival and disease-free survival in overall patients 

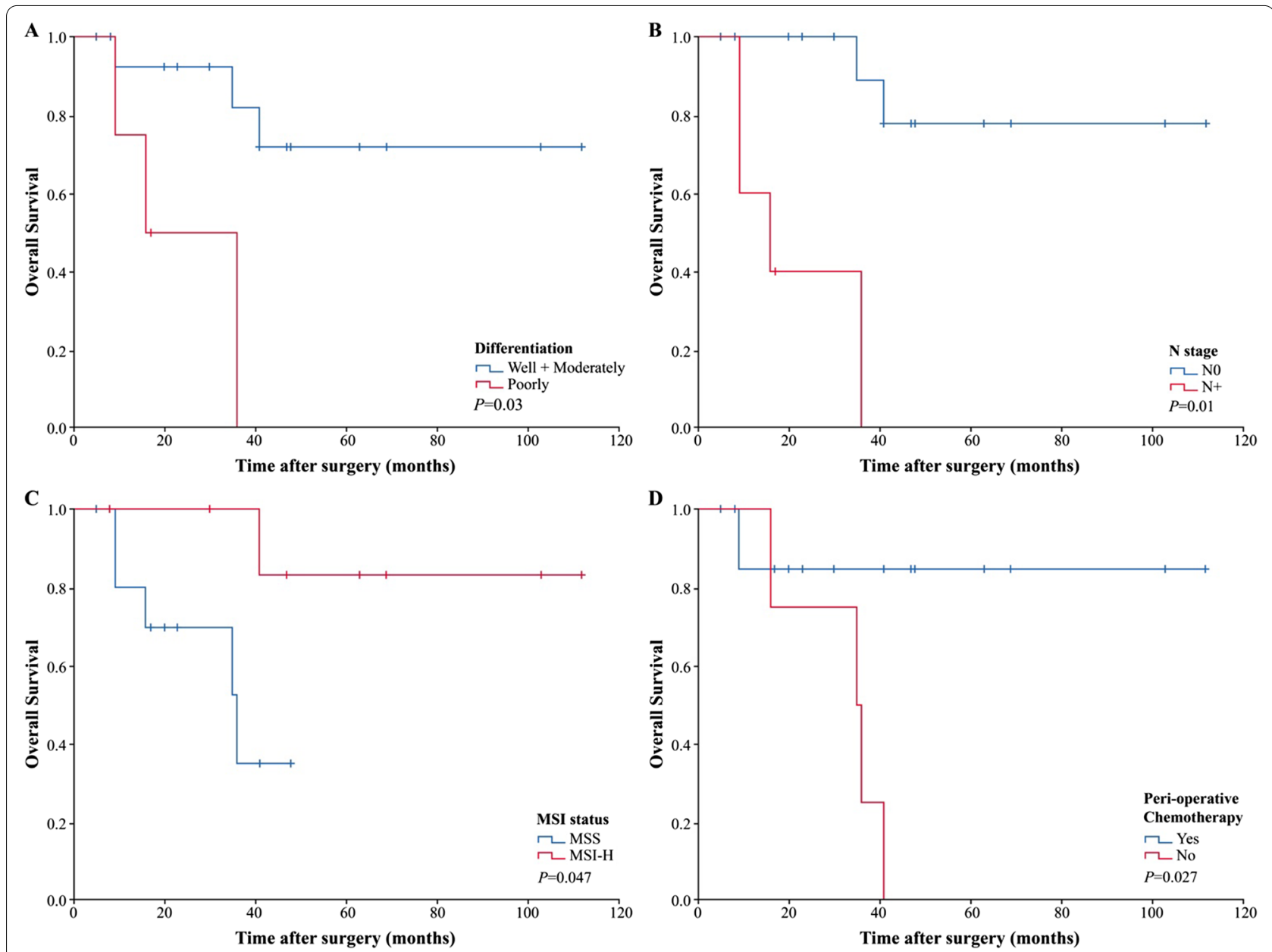

Fig. 2 Overall survival KM curves in patients of various groups. A Patients with well- or moderately differentiated tumor versus poorly differentiated tumor. B Patients with NO stage versus N+ stage. C Patients with MSS versus MSI-H. D Patients with adjuvant chemotherapy versus no chemotherapy. MSI-H microsatellite instability-high, MSS microsatellite stable

most common. No patient had DGE, ileocolic, gastrojejunal, or jejunojejunal anastomotic leak. A total of 15 patients received adjuvant chemotherapy, including XELOX (9 patients), FOLFOX4 (1 patients), mFOLFOX6 (1 patient), FOLFIRI (1 patients), Capecitabine (1 patients), FOLFOXIRI + Bevacizumab (1 patients), and XELOX + Bevacizumab + Pembrolizumab (1 patients), in which 4 patients received neoadjuvant chemotherapy. (Table 1).

\section{Pathologic findings and genetic testing}

Tumors were classified as well-differentiated adenocarcinoma (3 patients), moderately differentiated adenocarcinoma (12 patients), and poorly differentiated adenocarcinoma (4 patients) based on histologic findings. According to the AJCC classification system, 14 patients were N0 staged, 2 as N1b, 1 as N2a and 2 as N2b. All of the tumors had clear resection margins (R0).
In mutation testing, 11 patients were K-Ras mutant, 1 patient was B-Raf V600E mutant, 2 were Her-2 mutant, and none of the patients were N-Ras mutant as identified by using NGS. A total of 8 patients were identified as MSI-high status.

\section{Prognostic factors for overall survival}

On the basis of the univariate analysis, tumor differentiation, $\mathrm{N}$ stage, MSI status, and adjuvant chemotherapy were the significant prognostic factors $(P<0.05)$ (Table 2).

\section{Discussion}

Right-sided CRC invading duodenum and/or pancreas is a rare condition $[6,23,25]$, and only a few studies have reported adjacent-organ resection [4, 6, 7, 14-16, 25-29]. In our study, among 2269 patients with primary rightsided CRC who underwent radical RC screened, only 


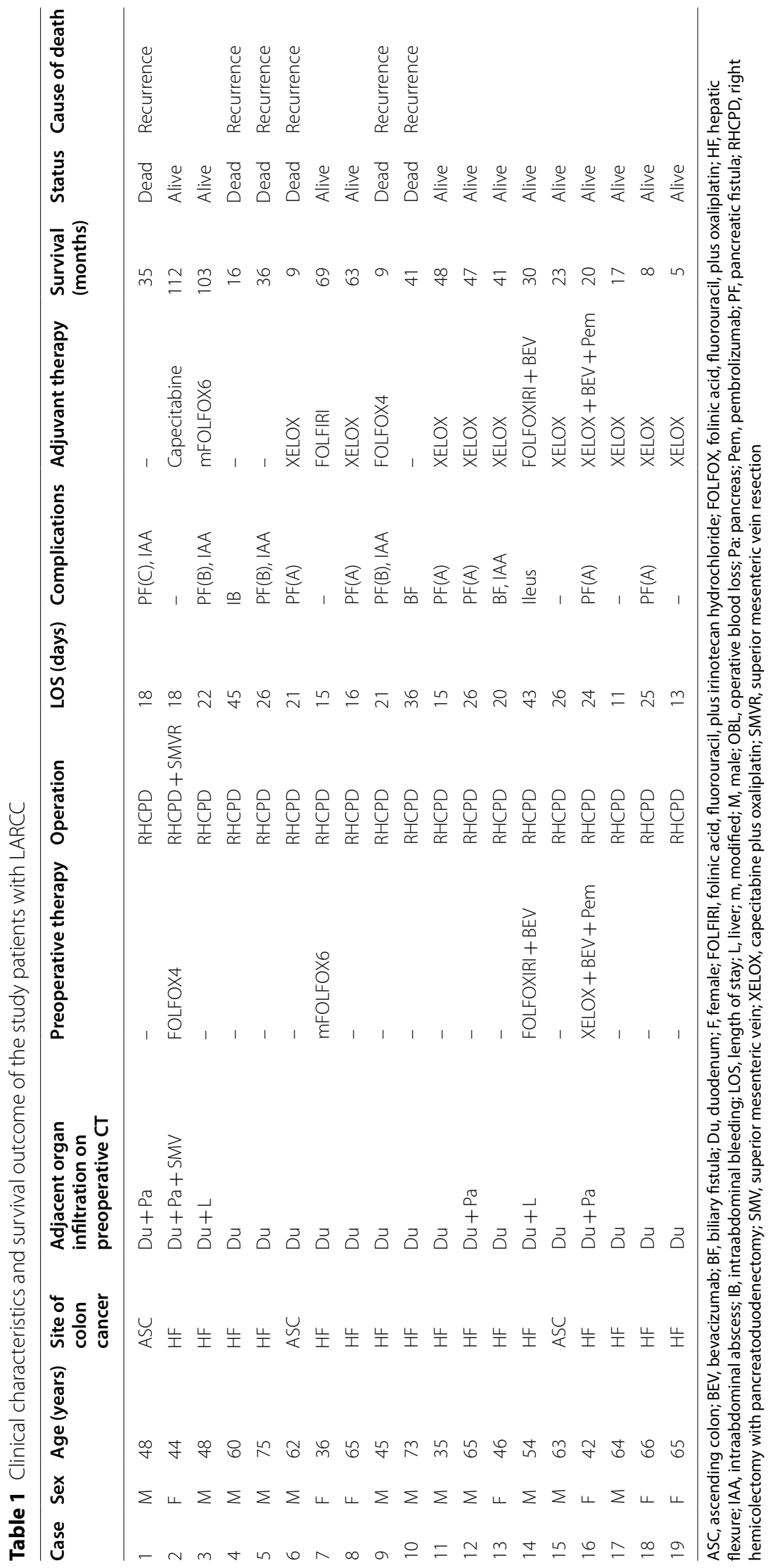


Table 2 Uni-analyses of factors associated with overall survival

\begin{tabular}{lll}
\hline Prognostic factors & & Univariable $\mathbf{P}$ \\
\hline Age, years & $<60 / \geq 60$ & 0.340 \\
Sex & Male/Female & 0.900 \\
Preoperative CEA & $<5 \mathrm{ng} / \mathrm{mL} / \geq 5 \mathrm{ng} / \mathrm{mL}$ & 0.877 \\
Preoperative CA19-9 & $<37 \mathrm{kU} / \mathrm{L} / \geq 37 \mathrm{kU} / \mathrm{L}$ & 0.646 \\
Operative time & $<320 \mathrm{~min} / \geq 320 \mathrm{~min}$ & 0.509 \\
Operative blood loss & $<400 \mathrm{~mL} / \geq 400 \mathrm{~mL}$ & 0.933 \\
Major complications & I/II-IV & 0.748 \\
Tumor differentiation & Poorly/well + moderately & 0.030 \\
N stage & No/N+ & 0.010 \\
MSI status & MSI-H/MSS & 0.047 \\
K-Ras & Wild/mutant & 0.888 \\
B-Raf & Wild/mutant & 0.771 \\
Her-2 & Wild/mutant & 0.635 \\
Adjuvant chemotherapy & Yes/no & 0.027 \\
\hline
\end{tabular}

CEA, Carcinoembryonic antigen, CA19-9 cancer antigen 19-9, MSI-H microsatellite instability-high, MSS microsatellite stable

19 patients (12 men and 7 women) underwent en bloc RHCPD for LARCC with direct infiltration into the duodenum and/or pancreas. The patients who underwent duodenal resection with correction by direct suture or pedicled ileal flap were excluded because of the poor outcome and high rate of morbidity and mortality. Cirocchi et al. summarized the results of 15 previous studies and reported a 5-years overall survival of $52 \%$ after en bloc pancreaticoduodenectomy plus right hemicolectomy vs. 0 and $25 \%$ in case of duodenal resection with correction by direct suture or pedicled ileal flap, respectively [8]. We agreed with the above views and tried to avoid local duodenectomy in clinical practice, LARCC once confirmed, all adhesions between tumor and adjacent organs should be considered as malignant invasion due to $33 \%$ to $84 \%$ malignant invasion on pathologic examination $[4,15]$ and should not be separated as there exist a risk of tumor recurrence rate of $90 \%$ to $100 \%[9,10]$. In our study, en bloc resection was performed, and adhesions were verified as malignant only after histopathologic examination.

Right-sided CRC invading duodenum and/or pancreas was considered to have poor outcomes and unresectable in the earlier days. However, recent studies have reported a promising prognosis, with a 5-year survival rate ranging from 21 to $55 \%$ in patients with LARCC invading adjacent organs undergoing en bloc multivisceral resection $[4,5,12,15,19]$. Similarly, in our study, all the patients who underwent curative RHCPD achieved good outcomes, with 1-, 3-, and 5-year OS rate of $88 \%, 66 \%$, and $58 \%$, whereas DFS rates of $72 \%, 56 \%$, and $56 \%$ respectively. Comparatively higher OS rate in our study is probably because of the fact that even though all the patients were staged $\mathrm{T} 4 \mathrm{~b}$, regional lymph node dissemination of the cancer may not be that advanced because only 5 out of 19 patients were lymph node positive (N2a and N1b). In addition, some colon cancers exhibits locally aggressive invasion instead of distant spread [4, 15, 27, 29]. According to the previous reports, $25 \%$ to $60 \%$ of right colon carcinoma that invaded the adjacent duodenum or pancreas do not have lymph node metastasis $[4,6,15$, $27,29]$. Furthermore, Saiura et al. reported significantly longer survival in patients with node-negative status than node-positive patients [15]. Similarly, in our study, the survival of patients with node-positive had short survival ( $<3$ years) at the time of last follow-up Meanwhile, the 3 - and 5-year OS of 14 patients with N0 were $89 \%$ and $78 \%$, respectively, among them 4 patients survived for $>5$ years. This is another reason why we recommend en bloc PD as superior to partial duodenectomy because partial resection is difficult to obtain extensive lymph node dissection.

Furthermore, based on the KM curve analysis, OS was significantly better in patients with well- or moderately differentiated tumor compared with patients with poorly differentiated tumor. This is probably because of the fact that the histologic type of tumor may affect the lymph node metastasis and prognosis in patients with LARCC as reported by a retrospective study conducted by Saiura et al. [15]. The rate of lymph node metastasis was significantly higher in well-differentiated adenocarcinoma than mucinous or poorly differentiated adenocarcinoma in LARCC $(P=0.015)$ [15]. In our study, only 1 patient (7\%) with moderately differentiated adenocarcinoma had node-positive status, whereas all the patients with poorly differentiation adenocarcinoma had node-positive status, and the 3-year OS rates of the two groups (well- or moderately differentiated tumor vs. poorly differentiation adenocarcinoma) were $82 \%$ versus $0 \%$.

Molecular markers such as K-Ras, N-Ras, B-Raf, HER2, and MSI play a significant role in the disease prognosis in CRC, and hence, analysis of these biomarkers helps in facilitating proper treatment to the needy patients [30]. In our study, all the patients in MSI-H status survived for $>3$ years, while 3-year OS of patients in MSS status was only $35 \%$. OS did not differ significantly between K-Ras mutant and wild-type, BRAF V600E mutant and wildtype tumors nor Her-2. Hence, only MSI was the significant prognostic factor affecting survival.

In FOxTROT trial, preoperative chemotherapy has resulted in significant downstaging of tumor in patients with locally advanced colon cancer compared to postoperative chemotherapy $(P=0.04)$ [31]. Another retrospective study by Arredondo et al. has also shown tumor downstaging (62.5\%), R0 resection (100\%), and a promising prognosis (median OS of 31 months) in locally 
advanced colon cancer patients treated with preoperative chemotherapy [32]. Similarly, in our study, the 3-year OS rates was greater in the preoperative and postoperative chemotherapy group (100\% and $77.8 \%$ ) compared with no perioperative chemotherapy group (25.0\%). However, these finding need to be confirmed by considering studies with large sample size.

There are several limitations associated with the present study. First, the number of LARCC patients with invasion of duodenum and/or pancreas is low, and hence, the number of participants is small in this study. Large-scale studies may produce more reliable results, nevertheless, our series is one of if not the largest series reported to date. Second, the chemotherapy regimens varied among patients. In the era of advanced chemotherapy, administering the same regimen for a long-term study seems formidable. However, the present study also has several strengths such as this study gathered the largest number of patients, and all the clinical information and follow-up were proved to be accurate. Moreover, histologic-genetic examination was performed in detail, and we were able to build a bridge between the preoperative clinical evidence with histologic-genetic findings and prognosis.

\section{Conclusions}

En bloc RHCPD may result in long-term survival in patients having LARCC with infiltrated adjacent organs. This aggressive approach may help improve the prognosis, particularly in patients with node-negative status. This study also evaluated the prognostic factors for OS and the role of mutational status of several genes on disease prognosis. Long-term and larger-scale studies may produce more reliable results.

\section{Abbreviations \\ AJCC: American Joint Committee of Cancer; Cl: Confidence interval; CRC: Colo- rectal cancer; CEA: Carcinoembryonic antigen; CA19-9: Cancer antigen 19-9; CT: Computed tomography; DFS: Disease-free survival; DGE: Delayed gastric emptying; HR: Hazard ratio; LARCC: Locally advanced right-sided colon cancer; MSI: Microsatellite instability; NGS: Next-generation sequencing; OS: Overall survival; PF: Pancreatic fistula; RHCPD: Right hemicolectomy with pancrea- toduodenectomy; RC: Right colectomy; SMV: Superior mesenteric vein.}

\section{Supplementary Information}

The online version contains supplementary material available at https://doi. org/10.1186/s12893-021-01286-0.

Additional file 1: Table 1. Clinical characteristics and treatments of the study patients with LARCC. Table 2 . Pathologic findings and genetic testing in the study patients.

\section{Acknowledgements}

The authors would like to thank Dr. Ming Liu, Dr. Wei Liu, Dr. Li-Jun Wang, and Dr. Da Xu for their operative support. Medical writing support was provided by Dr. Vedashree S and Dr. Amit Bhat, Indegene Pvt. Ltd., Bangalore, India.

\section{Authors' contributions}

$\mathrm{BCX}$ contributed to the conception and design. KW, QB, HWW and KMJ are responsible for the provision of the study materials and data collection. JYW contributed to the genetic testing. XLY contributed to the data analysis and interpretation and draft writing. All authors read and approved the final manuscript.

\section{Funding}

This study was supported by Grants (No. 81874143, No. 31971192) from the National Natural Science Foundation of China and Beijing Natural Science Foundation (No. 7192035). The funding body financed the costs of the study and contributed to the design of the study, interpretation of data, and revising the manuscript.

\section{Availability of data and materials}

All data generated or analysed during this study are available from the corresponding author on reasonable request.

\section{Declarations}

\section{Ethics approval and consent to participate}

This study was approved by the institutional ethical committee of the Beijing Cancer Hospital, and written informed consent was obtained from all the patients included in the study. All the procedures were performed in accordance with the 1964 Helsinki declaration and its later amendments.

\section{Consent for publication}

Written informed consent for publication was obtained from all participants.

\section{Competing interests}

JYW is employed by the company GloriousMed. The remaining authors declare that they have no competing interests.

\section{Author details}

${ }^{1}$ Key Laboratory of Carcinogenesis and Translational Research (Ministry of Education/Beijing), Hepatopancreatobiliary Surgery Department I, Peking University Cancer Hospital \& Institute, Beijing, China. ${ }^{2}$ CAS Key Laboratory of Genome Sciences and Information, Beijing Institute of Genomics, Chinese Academy of Sciences, Beijing, China. ${ }^{3}$ GloriousMed Holdings Co., Ltd., No.11, Lane 100, Banxia Road, Pudong New Area, Shanghai, China.

Received: 16 August 2020 Accepted: 3 June 2021

Published online: 29 June 2021

\section{References}

1. Bray F, Ferlay J, Soerjomataram I, Siegel RL, Torre LA, Jemal A. Global cancer statistics 2018: GLOBOCAN estimates of incidence and mortality worldwide for 36 cancers in 185 countries. CA Cancer J Clin. 2018;68:394424. https://doi.org/10.3322/caac.21492.

2. Baran B, Mert Ozupek N, Yerli Tetik N, Acar E, Bekcioglu O, Baskin Y. Difference between left-sided and right-sided colorectal cancer: a focused review of literature. Gastroenterol Res. 2018;11:264-73. https://doi.org/10. 14740/gr1062w.

3. Iguchi K, Mushiake H, Aoyama T, Suwa H, Yukawa N, Ota M, et al. Additional surgical resection after endoscopic resection for patients with high-risk T1 colorectal cancer. In Vivo. 2019;33:1243-8. https://doi.org/10. 21873/invivo.11596.

4. Kapoor S, Das B, Pal S, Sahni P, Chattopadhyay TK. En bloc resection of right-sided colonic adenocarcinoma with adjacent organ invasion. Int J Colorectal Dis. 2006;21:265-8. https://doi.org/10.1007/ s00384-005-0756-z.

5. Zhang J, Leng J, Qian H, Qiu H, Wu J, Liu B, et al. En bloc pancreaticoduodenectomy and right colectomy in the treatment of locally advanced 
colon cancer. Dis Colon Rectum. 2013;56:874-80. https://doi.org/10 1097/DCR.0b013e3182941704.

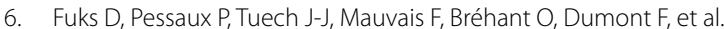
Management of patients with carcinoma of the right colon invading the duodenum or pancreatic head. Int J Colorectal Dis. 2008;23:477-81. https://doi.org/10.1007/s00384-007-0409-5.

7. Lee W-S, Lee WY, Chun H-K, Choi S-H. En bloc resection for right colon cancer directly invading duodenum or pancreatic head. Yonsei Med J. 2009:50:803-6. https://doi.org/10.3349/ymj.2009.50.6.803.

8. Cirocchi R, Partelli S, Castellani E, Renzi C, Parisi A, Noya G, et al. Right hemicolectomy plus pancreaticoduodenectomy vs partial duodenectomy in treatment of locally advanced right colon cancer invading pancreas and/or only duodenum. Surg Oncol. 2014;23:92-8. https://doi. org/10.1016/j.suronc.2014.03.003.

9. Perez RO, Coser RB, Kiss DR, Iwashita RA, Jukemura J, Cunha JEM, et al. Combined resection of the duodenum and pancreas for locally advanced colon cancer. Curr Surg. 2005;62:613-7. https://doi.org/10.1016/j.cursur. 2005.03.021.

10. Hunter JA, Ryan JA, Schultz P. En bloc resection of colon cancer adherent to other organs. Am J Surg. 1987;154:67-71. https://doi.org/10.1016/ 0002-9610(87)90292-3.

11. Noda H, Kato T, Kamiyama H, Toyama N, Konishi F. En bloc right hemicolectomy and pancreaticoduodenectomy with superior mesenteric vein resection for advanced right-sided colon cancer. Clin J Gastroenterol. 2010;3:259-61. https://doi.org/10.1007/s12328-010-0175-8.

12. Li D, Si X, Wan T, Zhou Y. A pooled analysis of en bloc right hemicolectomy with pancreaticoduodenectomy for locally advanced right-sided colon cancer. Int J Colorectal Dis. 2018;33:819-22. https://doi.org/10. 1007/s00384-018-2997-7.

13. Van Prohaska J, Govostis MC, Wasick M. Multiple organ resection for advanced carcinoma of the colon and rectum. Surg Gynecol Obstet. 1953:97:177-82

14. Kimchi ET, Nikfarjam M, Gusani NJ, Avella DM, Staveley-O'Carroll KF. Combined pancreaticoduodenectomy and extended right hemicolectomy: outcomes and indications. HPB. 2009;11:559-64. https://doi.org/10. 1111/j.1477-2574.2009.00087.x.

15. Saiura A, Yamamoto J, Ueno M, Koga R, Seki M, Kokudo N. Long-term survival in patients with locally advanced colon cancer after en bloc pancreaticoduodenectomy and colectomy. Dis Colon Rectum. 2008;51:154851. https://doi.org/10.1007/s10350-008-9318-0.

16. Kaneda Y, Noda H, Endo Y, Kakizawa N, Ichida K, Watanabe F, et al. En bloc pancreaticoduodenectomy and right hemicolectomy for locally advanced right-sided colon cancer. World J Gastrointest Oncol. 2017:9:372-8. https://doi.org/10.4251/wjgo.v9.i9.372.

17. Sheng Q-S, Chen W-B, Li M-J, Cheng X-B, Wang W-B, Lin J-J. Combined right hemicolectomy and pancreaticoduodenectomy for locally advanced right hemicolon cancer. Hepatobiliary Pancreat Dis Int. 2015;14:320-4. https://doi.org/10.1016/S1499-3872(15)60374-5.

18. Ağalar C, Canda AE, UnekT, Sokmen S. En bloc pancreaticoduodenectomy for locally advanced right colon cancers. Int J Surg Oncol. 2017. https://doi.org/10.1155/2017/5179686.

19. Zhao Y, Han G, Lu C, Ren Y, Li J, Ma P, et al. Right hemicolectomy and multivisceral resection of right colon cancer: a report of 21 cases. J Huazhong Univ Sci Technolog Med Sci. 2015;35:255-8. https://doi.org/10.1007/ s11596-015-1420-7.
20. Edge SB, Compton CC. The American Joint Committee on Cancer: the 7th edition of the AJCC cancer staging manual and the future of TNM. Ann Surg Oncol. 2010;17:1471-4. https://doi.org/10.1245/s10434-010-0985-4.

21. Bassi C, Dervenis C, Butturini G, Fingerhut A, Yeo C, Izbicki J, et al. Postoperative pancreatic fistula: an international study group (ISGPF) definition. Surgery. 2005;138:8-13. https://doi.org/10.1016/j.surg.2005.05.001.

22. Bassi C, Marchegiani G, Dervenis C, Sarr M, Abu Hilal M, Adham M, et al. The 2016 update of the International Study Group (ISGPS) definition and grading of postoperative pancreatic fistula: 11 Years After. Surgery. 2017;161:584-91. https://doi.org/10.1016/j.surg.2016.11.014.

23. Wente MN, Bassi C, Dervenis C, Fingerhut A, Gouma DJ, Izbicki JR, et al. Delayed gastric emptying (DGE) after pancreatic surgery: a suggested definition by the International Study Group of Pancreatic Surgery (ISGPS). Surgery. 2007;142:761-8. https://doi.org/10.1016/j.surg.2007.05.005.

24. Yun SH, Yun HR, Lee WS, Cho YB, Lee WY, Chun HK. The clinical outcome and prognostic factors after multi-visceral resection for advanced colon cancer. Eur J Surg Oncol. 2009;35:721-7. https://doi.org/10.1016/j.ejso. 2008.01.024.

25. Song X, Wang L, Zhan W, Wang J, He Y, Lian L, et al. Right hemicolectomy combined with pancreatico- duodenectomy for the treatment of colon carcinoma invading the duodenum or pancreas. Chin Med J (Engl). 2006;119:1740-3.

26. Lianwen Y, Jianping Z, Guoshun S, Dongcai L, Jiapeng Z. Surgical treatment for right colon cancer directly invading the duodenum. Am Surg. 2009;75:385-8

27. Koea JB, Conlon K, Paty PB, Guillem JG, Cohen AM. Pancreatic or duodenal resection or both for advanced carcinoma of the right colon: is it justified? Dis Colon Rectum. 2000;43:460-5. https://doi.org/10.1007/ BF02237187.

28. Harrison LE, Merchant N, Cohen AM, Brennan MF. Pancreaticoduodenectomy for nonperiampullary primary tumors. Am J Surg. 1997;174:393-5. https://doi.org/10.1016/S0002-9610(97)00121-9.

29. Curley SA, Evans DB, Ames FC. Resection for cure of carcinoma of the colon directly invading the duodenum or pancreatic head. J Am Coll Surg. 1994;179:587-92.

30. Afrăsânie V-A, Marinca MV, Alexa-Stratulat T, Gafton B, Păduraru M, Adavidoaiei AM, et al. KRAS, NRAS, BRAF, HER2 and microsatellite instability in metastatic colorectal cancer-practical implications for the clinician. Radiol Oncol. 2019;53:265-74. https://doi.org/10.2478/raon-2019-0033.

31. FOxTROT Collaborative Group. Feasibility of preoperative chemotherapy for locally advanced, operable colon cancer: the pilot phase of a randomised controlled trial. Lancet Oncol. 2012;13:1152-60. https://doi.org/ 10.1016/S1470-2045(12)70348-0.

32. Arredondo J, Martínez P, Baixauli J, Pastor C, Rodríguez J, Pardo F, et al. Analysis of surgical complications of primary tumor resection after neoadjuvant treatment in stage IV colon cancer. J Gastrointest Oncol. 2014:5:148-53.

\section{Publisher's Note}

Springer Nature remains neutral with regard to jurisdictional claims in published maps and institutional affiliations.

Ready to submit your research? Choose BMC and benefit from:

- fast, convenient online submission

- thorough peer review by experienced researchers in your field

- rapid publication on acceptance

- support for research data, including large and complex data types

- gold Open Access which fosters wider collaboration and increased citations

- maximum visibility for your research: over 100M website views per year

At BMC, research is always in progress.

Learn more biomedcentral.com/submissions 